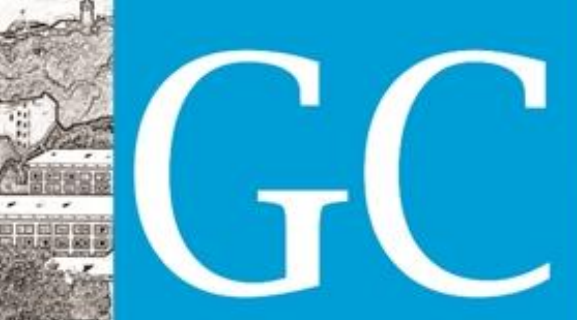

ISSN 2318-8472

v. 07, n. 49,2019

Revista Nacional de

Gerenciamento de Cidades

\title{
Levantamento do IAVP - Índice de Áreas Verdes Públicas
}

IAVP Survey - Public Green Areas Index

Encuesta IAVP - Índice de áreas verdes públicas

Sandra Medina Benini

Doutora em Arquitetura e Urbanismo; Docente do Centro Universitário de Várzea Grande - UNIVAG. arquiteta.benini@gmail.com

Jeane Aparecida Rombi de Godoy Rosin

Doutora em Arquitetura e Urbanismo; Docente do Centro Universitário de Várzea Grande - UNIVAG. urbanista.jeane@gmail.com 


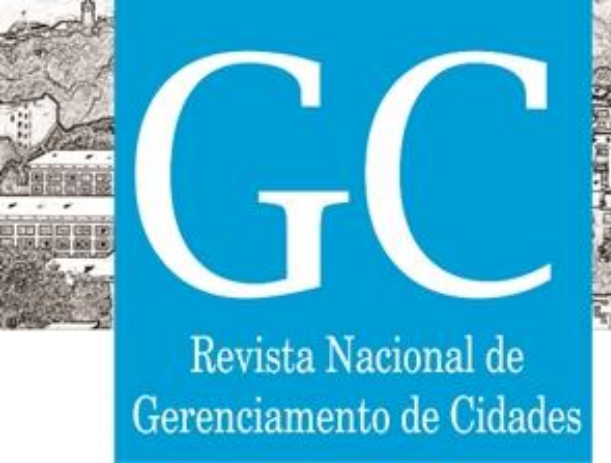

urbanización hubo una pérdida real de $16.02 \mathrm{~m}^{2} / \mathrm{h}$ de estos espacios debido a las coyunturas políticas de la ciudad. administración municipal; El IAVP actual de la ciudad es de $11.98 \mathrm{~m}^{2} / \mathrm{h}$, sin embargo, de este valor solo $1.75 \mathrm{~m}^{2} / \mathrm{h}$ se han urbanizado y constituyen el patrimonio paisajístico de la ciudad con 34 jardines públicos distribuidos en 20 subdivisiones; La evaluación cualitativa de estas 34 áreas verdes públicas mostró que el 60\% de estos espacios tuvieron resultados positivos, frente al $25 \%$ que se clasificaron como malos; Con respecto al confort ambiental de estos espacios, se encontró que debido al factor de escala, estas áreas verdes públicas tienen poca influencia en el clima urbano, y no contribuyen significativamente a la absorción de agua de lluvia.

Palabras clave: Áreas verdes públicas. Uso y ocupación del suelo urbano. Índice de área verde pública. 



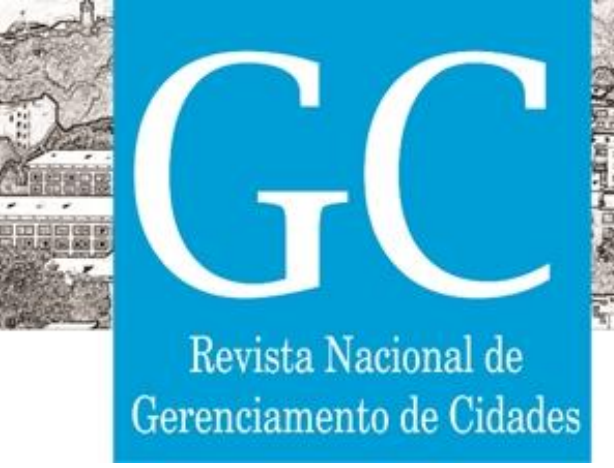

verde é uma categoria de espaço livre, desde que haja predominância de vegetação arbórea, como por exemplo: "praças, jardins públicos e parques urbanos".

Área Verde: onde há o predomínio de vegetação arbórea; engloba as praças, os jardins públicos e os parques urbanos. Os canteiros centrais e trevos de vias públicas, que têm apenas funções estética e ecológica, devem, também, conceituar-se como Área Verde. Entretanto, as árvores que acompanham o leito das vias públicas, não devem ser consideradas como tal. Como todo Espaço Livre, as Áreas Verdes também devem ser hierarquizadas, segundo sua tipologia (privadas, potencialmente coletivas e públicas). (LIMA et al., 1994, p.549).

Daltoé, Cattoni, Loch (2004, p. 3-4), propõem uma outra classificação sobre áreas verdes utilizada em seus estudos sobre a cidade de São José - SP. Os autores conseguem determinar seis categorias de áreas verdes.

Áreas verdes do sistema viário - Predominam vegetações de porte arbustivo e herbáceo. Representam os canteiros, trevos e rotatórias, associados ou não às redes de transmissão de energia. Apresentam-se com valor ecológico variando de baixo a médio e valor cênico médio. Por não possuírem nenhuma estrutura que possa atender às necessidades da população, possuem um baixo valor social.

Áreas verdes de uso particular - Predominam vegetações de porte arbóreo. Neste grupo estão situadas as áreas verdes que se apresentam em domínios de uso habitacional particular. São áreas inacessíveis para uso público devido à ausência de acessos e infra-estruturas. Seu valor ecológico é médio, enquanto o cênico e de conforto apresenta-se variando de médio a alto. Devido à impossibilidade de uso direto pelo público seu valor social varia entre médio e baixo.

Áreas verdes residuais - Áreas herbáceo-arbustivas com ou sem cobertura arbórea. Em geral, representam as áreas verdes em loteamentos recentes ou em fase de implantação. Não se enquadram na classificação quanto aos valores cênicos, sociais e ecológicos devido à instabilidade da situação de uso atual.

Áreas verdes institucionais - Possuem distintas configurações, representadas pelos jardins, áreas verdes de uso institucional, campos de futebol etc. Seu valor cênico é alto e seu valor ecológico e social é médio, devido à restrição de alguns equipamentos para uso da coletividade.

Áreas verdes públicas e/ou de uso coletivo - Nesse grupo enquadram-se as áreas verdes de composição mista com arborização significativa (espécies exóticas e nativas). Compreendem as praças, parques e bosques urbanos, assim como áreas arborizadas dentro dos complexos históricos. Possuem alto valor ecológico, cênico e social.

Áreas livres não arborizadas (vazios urbanos) - Compreendem as coberturas herbáceo-arbustivas (predominantemente gramíneas). Os lotes vazios, característicos principalmente em áreas urbanas de consolidação recente, 


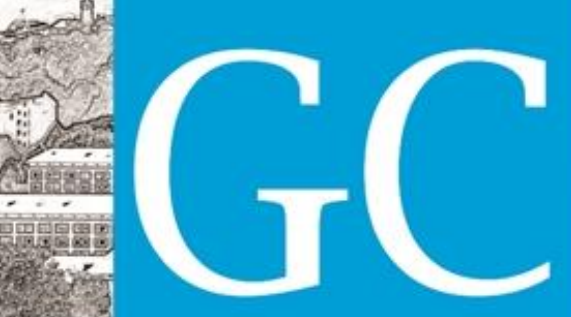

ISSN 2318-8472

Revista Nacional de

Gerenciamento de Cidades

Freitas-Lima e Cavalheiro (2003, p. 35) apontam a necessidade de se ter um conceito padrão, para que possa haver uma "análise comparativa entre os índices de áreas verdes" entre os sítios urbanos.

As diferentes definições do termo área verde dificultam uma análise comparativa entre os índices de ares verdes para as diferentes cidades. Dependendo da concepção do termo área verde, ao computados nos índices de tais áreas, espaços públicos ou particulares, permeáveis ou não, unidades de conservação ambiental, verde de acompanhamento viário e, até mesmo, arborização de ruas. (FREITASLIMA; CAVALHEIRO, 2003, p. 35)

Diante dos apontamentos, Freitas-Lima e Cavalheiro (2003) ressaltam a necessidade da formulação de um conceito mais unânime sobre áreas verdes.

\section{Metodologia}

Para a delimitação do universo a ser estudado, optou-se por uma pesquisa qualitativa, em que os procedimentos tiveram uma base lógica que consistiu na investigação dividida em três fases: "aberta ou exploratória", "coleta de dados" e "análise e interpretação sistemática dos dados" (LÜDKE; ANDRÉ, 1986, p. 21).

A primeira fase da pesquisa, conhecida como aberta ou exploratória, consistiu no exame da literatura pertinente, onde foi constado nos trabalhos científicos (livros, teses, dissertações, artigos, etc.) sobre a temática, a repetição constante dos mesmos referenciais bibliográficos, sem apresentação de novas proposituras, as quais viessem a ampliar a discussão teórica.

A coleta dos dados foi realizada a partir das informações disponibilizadas pela SEPLIN - Secretaria de Planejamento e Infraestrutura da Prefeitura da Estância Turística de Tupã, que permitiram realizar uma análise sistematizada sobre a temática proposta, através de dados coletados no acervo público do imobiliário urbano, da base cartográfica do SIG - Sistema Informações Georeferenciadas e do Censo Municipal realizado em julho de 2007.

No acervo público do imobiliário urbano foram coletadas informações detalhadas dos loteamentos da cidade de Tupã, permitindo compreender como se deu o processo de ocupação e uso do solo urbano e as características peculiares destes empreendimentos.

A terceira fase consistiu na inserção do objeto de pesquisa dentro de um quadro de referenciais teóricos, concomitantemente com a construção empírica, o que permitiu a definição dos procedimentos metodológicos necessários à obtenção dos produtos desta pesquisa.

\section{Estudo de Caso}

Para o desenvolvimento deste trabalho, optou-se como recorte espacial a cidade de Tupã (Município

- Estância Turística de Tupã-SP), localizada na região sudoeste do Estado de São Paulo. Os limites 

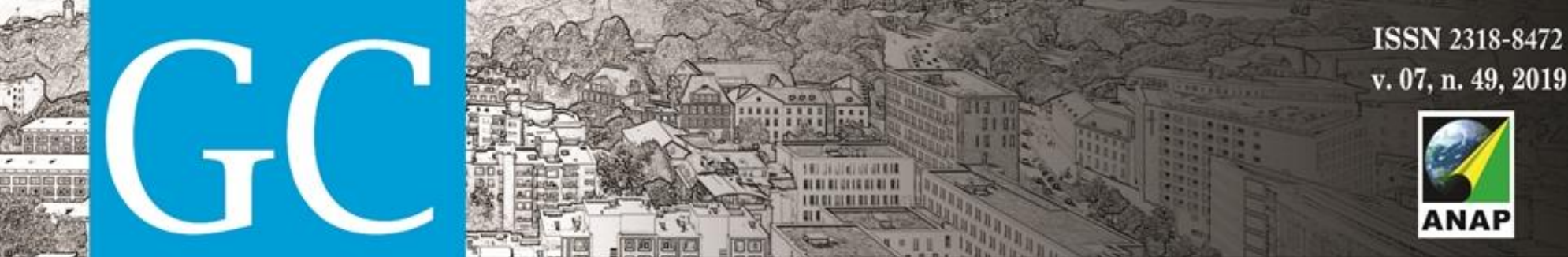

Revista Nacional de

Gerenciamento de Cidades

A expansão urbana deste sítio foi marcada como novos traçados, a exemplo do linear o qual permitia a composição de uma densidade mais uniforme, circulação fácil (FERRARI, 1977). Esse processo de expansão foi ressaltado pela ocupação dos fundos de vales e por áreas periféricas na malha urbana, resultado da intervenção de diferentes agentes sociais (usuário e loteador) e o Estado.

Segundo Glusberg (1996, p. 84), o espaço público é um dos "componentes que fazem com que a cidade esteja habilitada para exercer sua natureza e função res publica - coisa de todos, coisa pública" onde "a ordem espacial é entendida como uma condição para que as ações sociais e coletivas se produzam". Neste entendimento, Barbirato, Souza, Torres (2007, p.144) afirmam

[...] que o espaço público além de se configurar como local de convívio e encontro, pode ser identificado, como palco de expressões e exercício da cidadania, assumindo extrema importância no contexto da vida urbana. (BARBIRATO; SOUZA; TORRES, 2007, p.144)

Apesar de Barbirato, Souza, Torres (2007, p.144) identificarem os espaços públicos como locais de "exercício da cidadania", Lefebvre (1992, p. 349), defende que estes espaços ocultam interesses políticos para o controle social, os quais são resguardados por propostas de "[...] neutralidade, de insignificância, de destituição semiológica e de vazio (ou ausência)". Para Sobarzo (2006, p.98), a criação e reprodução desses espaços públicos, têm caráter político, pois em regra, tornam-se uma "moeda de troca para fins eleitorais".

As diferentes administrações municipais procuram deixar as suas marcas no espaço público, assim como o utilizam como moeda de troca para fins eleitorais. Nesse sentido, as inaugurações e re-inaugurações de calçadas, parques e praças - além de outras obras, serviços ou equipamentos públicos - dificilmente são realizadas como se essas ações fossem consideradas próprias e cabíveis à administração municipal. Pelo contrário, as obras são apresentadas como corporificação da preocupação e da capacidade especial da autoridade. Assim, a obra fica personalizada e o voto fica comprometido, reproduzindo as relações de patrimonialismo e clientelismo que perpassam a sociedade brasileira desde tempos coloniais. (SOBARZO, 2006, p.98)

É notório que cada gestão pública será marcada pelo comprometimento, ação ou omissão de seus administradores. Para Robba e Macedo (2003, p. 46) quando o Poder Público cria ou faz a manutenção desses espaços públicos, necessariamente, suas ações estão sujeitas à aprovação ou não da opinião pública, acarretando ou não em benefícios políticos.

Objetivando a mudança dessas práticas, o Estatuto da Cidade (Lei Federal no 10.257/2001), impôs a participação popular como requisito necessário ao planejamento urbano, em especial na elaboração

\footnotetext{
2 Segundo Ferrari (1977), o sistema ou estrutura ortogonal consiste de ruas que se cruzam em ângulo reto formando quadrados (tabuleiro xadrez) ou retângulo (grelhas ou grades).
} 


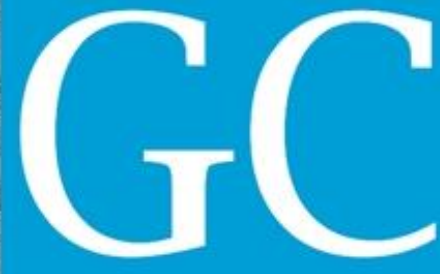

Revista Nacional de

Gerenciamento de Cidades

Dentre os resultados obtidos, a Tabela 1 - Síntese dos Índices de Áreas Verdes Públicas demonstra que a maior disparidade de valores está entre os Índices de Áreas Verdes Públicas Aprovadas ${ }^{5}$ os Índices de Áreas Verdes Urbanizadas'.

Tabela 1 - Síntese dos Índices de Áreas Verdes Públicas da Cidade de Tupã/SP (1929 a 2007)

\begin{tabular}{|c|c|c|c|c|c|c|}
\hline \multirow{2}{*}{$\begin{array}{c}\text { No } \\
\text { DE } \\
\text { CAD. }\end{array}$} & \multirow[b]{2}{*}{ QUALIFICAÇÃO } & \multirow[b]{2}{*}{ LOTEAMENTO } & \multirow[b]{2}{*}{ SETOR } & \multicolumn{3}{|c|}{ ÍNDICES DE ÁREAS VERDES PÚBLICAS ( $\left.\mathrm{m}^{2} / \mathrm{h}\right)$} \\
\hline & & & & IAVP APROVADAS & IAVP ATUAIS ${ }^{7}$ & $\begin{array}{c}\text { IAVP } \\
\text { URBANIZADAS }\end{array}$ \\
\hline 40 & JARDIM & IDEAL & LESTE & 58,74 & 0,00 & 0,00 \\
\hline 41 & JARDIM & SANTO ANTÔNIO & LESTE & 0,17 & 0,00 & 0,00 \\
\hline 51 & VILA & SANTA RITA DE CÁSSIA & SUL & 1,07 & 0,00 & 0,00 \\
\hline 75 & JARDIM & SANTA MARIA & LESTE & 2,08 & 2,08 & 0,00 \\
\hline 77 & JARDIM & ARITANA & LESTE & 26,74 & 9,45 & 0,00 \\
\hline 78 & JARDIM & ITAIPU & LESTE & 5,05 & 0,90 & 0,00 \\
\hline 79 & JARDIM & APOENA & LESTE & 14,57 & 1,15 & 0,00 \\
\hline 80 & JARDIM & JAÇANÃ & LESTE & 19,43 & 8,24 & 0,00 \\
\hline 81 & & DELTA VILLE TÊNIS CLUBE & LESTE & $1.216,12$ & 0,00 & 0,00 \\
\hline 83 & JARDIM & CYBELLE & LESTE & 11,06 & 11,06 & 0,00 \\
\hline 86 & VILA & FAUT & OESTE & 9,13 & 0,00 & 0,00 \\
\hline 87 & JARDIM & SANTA ADÉLIA & LESTE & 22,92 & 5,18 & 0,00 \\
\hline 88 & VILA & ELDORADO & LESTE & 14,75 & 0,00 & 0,00 \\
\hline 89 & VILA & ALTO SUMARÉ & LESTE & 27,55 & 2,19 & 0,00 \\
\hline 92 & PARQUE & SÃO PEDRO & LESTE & 14,15 & 10,99 & 0,00 \\
\hline 94 & JARDIM & UNESP I & LESTE & 13,41 & 0,00 & 0,00 \\
\hline 103 & CONJ. HAB. & $\begin{array}{c}\text { SEVERINO FORTUNATO DA } \\
\text { SILVA }\end{array}$ & LESTE & 13,00 & 13,00 & 0,00 \\
\hline 104 & CONJ. HAB. & WALTER PIMENTEL & LESTE & 24,84 & 18,34 & 0,00 \\
\hline 105 & CONJ. HAB. & $\begin{array}{l}\text { JOSÉ MARIA GONÇALVES } \\
\text { GAMEIRO }\end{array}$ & LESTE & 10,66 & 9,37 & 0,00 \\
\hline 109 & JARDIM & CHÁCARA VELINI & LESTE & 55,13 & 0,00 & 0,00 \\
\hline
\end{tabular}

${ }^{5}$ IAVP Aprovada - Índice de Área Verde Pública Aprovada é a razão entre todas as áreas verdes públicas (que foram afetadas como de uso comum no ato do registro dos loteamentos da cidade de Tupã) e a população (Censo Municipal de 2007) de cada loteamento (Lei de Parcelamento do Solo Urbano, no 6.766, de 19 de Dezembro de 1979, alterada pela Lei no 9.785, de 29 de Janeiro de 1999; e, SEPLIN).

${ }^{6}$ IAVP Urbanizada - Índice de Área Verde Pública Urbanizada considerou todas as áreas verdes públicas que permaneceram afetadas como de uso comum e têm instalados equipamentos e mobiliários, nos loteamentos da cidade de Tupã e dividiuse pela população (Censo Municipal de 2007) de cada loteamento (Lei de Parcelamento do Solo Urbano, no 6.766, de 19 de Dezembro de 1979, alterada pela Lei no 9.785, de 29 de Janeiro de 1999; e, SEPLIN).

7 IAVP Atual - Índice de Área Verde Pública Atual é obtido do quociente entre todas as áreas verdes públicas que permaneceram afetadas como de uso comum dos loteamentos da cidade de Tupã e a população (Censo Municipal de 2007) de cada loteamento (Lei de Parcelamento do Solo Urbano, no 6.766, de 19 de Dezembro de 1979, alterada pela Lei $n$ ㅇ 9.785, de 29 de Janeiro de 1999; e, SEPLIN). 


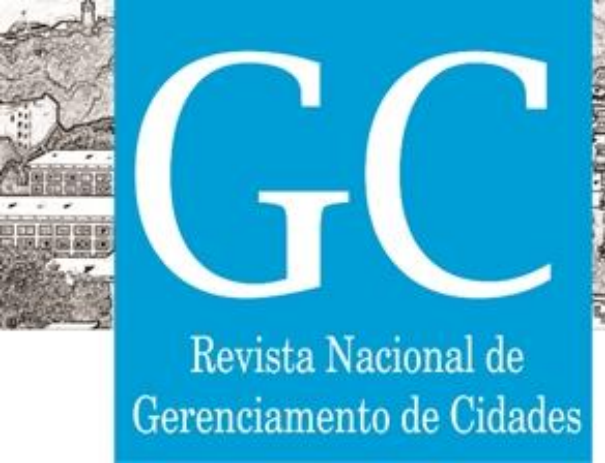

ROBBA, F; MACEDO, S. S.. Praças brasileiras: public squares in Brazil. São Paulo: Edusp: Imprensa oficial do Estado. 2002, 312p.

SEADE. Índice de Desenvolvimento Humano Municipal - IDHM. Disponível em: < http://produtos.seade.gov.br/produtos/perfil/perfilMunEstado.php > Acesso 20 ago. 2014.

SOBARZO, Oscar. A apropriação do espaço público: da dominação à apropriação. GEOUSP - Espaço e Tempo, São Paulo, no 19, pp. 93 - 111, 2006. Disponível em:

<http://www.geografia.fflch.usp.br/publicacoes/Geousp/Geousp19/Artigo_Sobarzo.pdf>Acesso em: 21 mai. 2008.

VAINER, C. B.; SMOLKA, M. O. Em tempos de liberalismo: tendências e desafios do planejamento urbano no Brasil in: PIQUET, R.; RIBEIRO, A. C. T. Brasil, território da desigualdade: descaminhos da modernização. Rio de Janeiro: Jorge Zahar (editor) e Fundação Universitária José Bonifácio, 1995. 